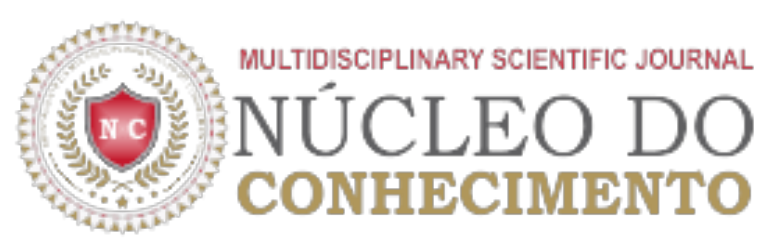

\title{
As Novas Tecnologias da Informação e Comunicação e a Concepção de Alunos do Curso de Ciências Contábeis da Faculdade de Iporá ${ }^{[1]}$
}

\author{
MARTINS, Cleuza Joana de Lima ${ }^{[2]}$
}

MARTINS, Cleuza Joana de Lima. As Novas Tecnologias da Informação e Comunicação e a Concepção de Alunos do Curso de Ciências Contábeis da Faculdade de Iporá. Revista Científica Multidisciplinar Núcleo do Conhecimento. Ano 03, Ed. 03, Vol. 01, pp. 110-161, Março de 2018. ISSN: 2448-0959

\section{RESUMO}

Esse estudo tem como objetivo analisar como se desenvolve a relação entre o processo ensinoaprendizagem do aluno e o uso das tecnologias educacionais. Considerando o exposto, esta pesquisa teve como objetivo geral demonstrar a influência das TICs no processo de ensino aprendizagem na educação atual. Como objetivos específicos determinaram-se os seguintes: compreender o uso das tecnologias como prática de ensino; demonstrar a influência das TICs no processo de ensino aprendizagem, na educação atual; investigar a formação de professores no âmbito do uso de tecnologias educacionais e de comunicação e analisar a concepção dos professores em relação à contribuição da tecnologia para o processo de ensino e sua prática em sala de aula, assim como o gosto dos alunos pelas aulas e sua aprendizagem. Trata-se de uma pesquisa bibliográfica, que utilizou livros e periódicos impressos e eletrônicos. Para os periódicos optou-se por um corte cronológico compreendido entre 1980 a 2012, já para os livros observou-se apenas a problemática em questão. Trata-se de investigação de cunho qualitativo em que foram utilizados como instrumentos de pesquisa entrevistas semiestruturadas com oito professores do curso de Ciências Contábeis de uma Faculdade da rede privada de ensino. O estudo aponta a contribuição dos recursos tecnológicos em sala de aula, e a necessidade de melhor formação de professores para o uso das mídias, com uma prática pedagógica reflexiva e transformadora.

Palavras-chave: Educação, Novas Tecnologias, Prática Educativa, Professor.

\section{INTRODUÇÃO}


A educação contemporânea tem sido marcada pela utilização de recursos tecnológicos em sala de aula, que tem contribuído no aprendizado e no interesse dos alunos pela escola, no entanto tem exigido melhor formação de professores para o uso das mídias, com uma prática pedagógica reflexiva e transformadora.

É comum no meio acadêmico a preocupação acerca da utilização das Tecnologias da Informação e Comunicação - TIC como ferramentas no processo de ensino - aprendizagem, acarretando grandes debates sobre o uso desta ferramenta em sala de aula. De um lado profissionais defendem a inserção dessas tecnologias no processo educacional, outros acreditam que ao utilizarem essas tecnologias na sala de aula contribuirá para o comodismo do aluno que deixam de desenvolver habilidades de raciocínio, criatividade e autonomia. Desse modo, tem-se um desafio aos docentes que deverão buscar conhecimento para a utilização dessas tecnologias, pois ele cada vez mais deixa de ser o detentor da transmissão do conhecimento.

Acredita-se que o uso de recursos tecnológicos na sala de aula contribui para uma aprendizagem mais significativa e contextualizada, porém muitos docentes ainda têm resistência quanto ao manuseio das novas tecnologias, já outros compreendem os subsídios que os recursos tecnológicos oferecem.

Surge assim, o interesse por esta pesquisa, na busca de informações que possam ajudar a identificar as competências que devem ser adotadas pelo professor voltadas ao uso de tecnologias, visando à transformação de sua prática pedagógica no processo de ensino e aprendizagem, bem como as concepções dos alunos acercas dessas práticas. As Tecnologias de Informação e Comunicação são muito importantes para facilitar o processo de ensino aprendizagem dos membros da unidade escolar.

Portanto, o presente trabalho foi idealizado na tentativa de expor dificuldades e potencialidades das tecnologias da informação e comunicação quanto ao processo educativo, tendo como objetivo geral demonstrar a influência das TICs no processo de ensino aprendizagem, na educação atual. Tendo ainda como objetivos específicos: compreender o uso dessas tecnologias, como prática de ensino; demonstrar a influência das TICs no processo de ensino aprendizagem, na educação atual; investigar a formação de professores no âmbito do uso de tecnologias educacionais e de comunicação e analisar a concepção dos professores em relação à contribuição da tecnologia para o processo de ensino e sua prática em sala de aula, assim como o gosto dos alunos pelas aulas e sua aprendizagem.

Com o intuito de investigar sobre a relação entre o processo ensino-aprendizagem do aluno e o uso das tecnologias educacionais, começaram a surgir os seguintes questionamentos para professores e alunos: Como os alunos concebem o uso das tecnologias na educação? De que maneira a influência tecnológica educacional vem contribuindo para a educação?

Com o intuito de alcançar os objetivos deste estudo, a investigação se fundamentou nos princípios da pesquisa qualitativa, em forma de estudo de caso, no qual houve discussões temáticas debatidas e vivenciadas por oito professores do curso de Ciência Contábeis de uma Faculdade da rede privada de ensino. Foram realizadas entrevistas semiestruturadas com professores e aplicado questionários aos alunos envolvidos no processo de pesquisa. Todos os participantes da pesquisa foram identificados por códigos, a saber: professores receberam a denominação de (professor 1, 2 e 3 ) e os alunos de (aluno A, B, C, D, E, F, G e H).

As entrevistas foram feitas individualmente e com a preocupação de deixar o entrevistado à vontade para 
falar tudo o que desejava sobre o assunto, obtendo assim, a maior quantidade de informação possível.

Acredita-se que esta pesquisa possa contribuir de forma reflexiva para a compreensão da relevância da inserção das tecnologias no projeto pedagógico da escola, bem como seguir suas tendências para melhoria da aprendizagem, da qualidade do ensino e, consequentemente, a preparação para o futuro dos discentes.

Para uma melhor compreensão do trabalho foi dividido em três capítulo, sendo que o primeiro relata sobre a importância dos recursos tecnológicos no sistema educacional, destacando a formação de professores no âmbito do uso de tecnologias educacionais e de comunicação; evidencia as novas tecnologias em um cenário educacional.

O segundo capítulo relata sobre a metodologia tendo em vista a realização da pesquisa apontando os benefícios e fragilidades das TICs na construção de novos saberes.

No terceiro capítulo foram abordados os resultados e a discussão encontrada na referida pesquisa, obtidos no estudo de campo, bem como as considerações finais, propondo sugestões de melhorias no tocante ao tema.

\section{Novas tecnologias da informação e comunicação: História e conceitos}

\subsection{Conceitos}

As tecnologias da informação e comunicação (TIC's), são ferramentas de grande importância para a educação e os profissionais da mesma, pois auxilia muito na mediação do conhecimento. O professor ao usar ferramentas tecnológicas como o computador em sala se torna um mediador, pois o mesmo não é o dono do saber.

Segundo o dicionário de filosofia de Nicola Abbagnano (1982, p. 906), a tecnologia é o estudo dos processos técnicos de um determinado ramo de produção industrial ou de mais ramos.

Nas reflexões de Vieira Pinto (2005) sobre Tecnologia ele a define como conjunto de todas as técnicas de que dispõe determinada sociedade. Trata de uma linguagem do cotidiano quando normalmente, não há necessidade de precisão conceitual. Conforme o autor a técnica ganha mais centralidade, do que o ser humano que reside no local que irá recebê-la. O autor compara ainda o conceito de técnica com a ideologização da tecnologia, onde menciona a ideologia da técnica, quando fica estabelecida certa relação entre o estado de desenvolvimento das técnicas e a elevação delas à ideologia social. Envolve um estado de espírito eufórico e uma cresça no seu poder demiúrgico. Afirma o autor que supostamente, o ser humano, por meio da tecnologia, irá construir uma vida feliz para todos. Afirma também que o ser humano, na ideologização em vez de fazer da máquina instrumento de transformação a vê como instrumento de adoração e que não é atoa que muitos atribuem nomes próprios a essas máquinas como se fossem serem vivos. Diz ainda que a máquina representa o aspecto estático e incorpora um programa de ação, visível na sucessão de atos que ela própria executa.

A tecnologia para Vieira Pinto (2005), torna-se a grande ideologia do nosso tempo justamente em função desses interesses políticos; tecnologia que, de fato, obtém significativa utilidade no "enfeitiçamento da maioria da população". O autor acrescenta ainda, as formas de ideologização da tecnologia como sendo 
incluir o esforço para mostrar que a tecnologia supostamente mais avançada só pode ser fruto dos países centrais; procurar mostrar que a técnica desenvolvida nos países centrais é uma "benção para a humanidade em geral" e denunciar que as tentativas de se opor a esse desenvolvimento tecnológico correspondem a uma visão retrógrada de estudiosos românticos. Fala ainda dos resultados desta ideologização da tecnologia com sendo: revestir a sociedade de valor ético positivo e utilizar a técnica como instrumento para silenciar as manifestações políticas. Alerta ainda que a nova tecnologia tem de se relacionar à antiga, mesmo que, venha a ocorrer entre elas um salto evolutivo e acrescente que a realidade das massas ou das sociedades "não tecnológicas" não pode ser vista como se estas fossem destituídas de tecnologia. Para ele transplantar tecnologia como se não existisse alguma instalada é pressupor que a máquina faz o ser humano e não que o ser humano faz a máquina.

\subsection{Das tecnologias as novas tecnologias: visão histórica}

\subsubsection{Elementos históricos sobre a mídia}

Ao longo do XX, especialmente entre os anos 1940 e 1970, o telefone, o cinema, o rádio, as revistas e a televisão constituíram-se em um sistema, que o desenvolveu-se, transformou-se em aparato de última geração ao integrar outros avanços tecnológicos mais recentes como telefones, TV interativa e a internet. Tais aparatos foram sendo produzidos e vinculados com a totalidade, estabelecendo uma íntima relação com os objetivos da industrialização (BRANDÃO, 2002).

Desde a década de 1980, Rezende e Fusari (1995, p. 68) enfatizavam que o papel da escola na produção social da comunicação emancipatória com as mídias precisava ser estudado e aperfeiçoado. Era preciso "aprender a elaborar e a intervir no processo comunicacional que se dá entre professores e alunos com essas mídias, para ajudar na realização da cidadania contemporânea".

A evolução da humanidade e a globalização, fez com que várias fronteiras fossem diminuídas, a fim de ampliar e aproximar os processos culturais, sociais e históricos. No momento de transformação constante da política, da economia e acima de tudo da educação, as adaptações estruturais e pedagógicas das escolas direcionam-se a um novo contexto social, onde a implantação da tecnologia é muito importante.

Um grande incentivo às mudanças é a chegada dos equipamentos tecnológicos à escola (TV, vídeo, computadores), porém apenas a presença física dos equipamentos não qualifica as mudanças. As mudanças profundas ocorrem quando realmente existe interação entre os atores educacionais e a máquina, sendo esta utilizada como estruturante do saber. (OLIVEIRA, 2007.p.5).

As tecnologias estão transformando amplamente as convivências sociais. As informações são transmitidas rapidamente, transformam assim todos em seu modo de agir, ser e de pensar, e além de fazer uma leitura crítica do mundo, onde cada pessoa é capaz de ver o que há ou não de útil para sua vida (MERCADO, 1999).

Os meios digitais ou ferramentas tecnológicas, são ótimos auxiliares para os professores quando se trata de envolver os alunos em sala, além de deixar a aula mais agradável e prazerosa, faz com que os alunos sejam agentes ativos no processo de ensino aprendizagem.

A tecnologia não é uma panaceia para a reforma do ensino, mas ela pode ser um canalizador significativo 
para a mudança. Para aquele que procuram uma solução simples e inovadora, a tecnologia não é resposta. Para aqueles que procuram uma ferramenta poderosa para apoiar ambientes de aprendizagem colaborativos a tecnologia tem um enorme potencial (SANDHOLTZ, 1997. p.175).

A escola deve oferecer ferramentas necessárias para que o professor possa fazer um ensino de qualidade, oferecendo recursos e materiais adequados e diversificados para facilitar o seu trabalho.

As tecnologias usadas em sala de aula contribuem muito para uma interatividade entre alunos e conhecimento, alunos e professores, pois os alunos se sentem mais à vontade quando se utiliza o computador. Alguns se sentem mais à vontade de relatar algo e escrever textos no computador do que se expressar para o professor ou para os colegas (SOUZA e ZAKABI, 2006).

As Tecnologias de Informação e Comunicação (TIC) oferecem recursos para favorecer e enriquecer as aplicações e os processos, principalmente na área de educação. A adoção dos recursos das TIC para a aprendizagem abre novas possibilidades para complementar a educação formal. (CARITÁ, PANDOVAN, SANCHES, 2011, p.2).

Com o computador em sala de aula, os alunos podem criar algo e compartilhar com o professor e seus colegas sala. É valido lembrar que textos ou imagens criados por um aluno não precisam ficar expostos apenas para seus colegas e professores. Ao usar a rede mundial de computadores o mundo todo pode ter acessos aos trabalhos e criações de cada indivíduo (VALENTE, 2005).

Essa divulgação on-line de trabalhos poderá ajudar o aluno a se desenvolver suas habilidades, pois, ao mesmo tempo em que algo é disponibilizado na internet, pode receber comentários os quais podem levar ao crescimento cultural e intelectual, ou até mesmo crítica construtiva que contribuirá para o aprimoramento no seu trabalho. Caberá ao mesmo considerar o que irá ou não ajudá-lo em seu desenvolvimento (BELLONI, 2001).

O papel do computador como mediador, interfere de forma complexa e ambivalente em nossos processos mentais por apresentar características ao mesmo tempo semelhantes e diferentes das nossas: transformação da representação e do raciocínio em objetos manipuláveis através do seu poder em registrálos numa memória ilimitada e inalterada; rapidez de execução dos comandos e efeitos recursivos, ou seja, a volta sistemática da informação sobre si mesma. Tudo isso produz formas de interatividade e ritmos novos, que levam os efeitos diversos, positivos, não só no plano cognitivo da aprendizagem, como também no plano psico afetivo e social. (LINARD, 1990, P.86).

É dever do educador, escolher se deverá incluir tais ferramentas em seu método de ensino ou apenas deixá-las de lado. Quando acontece essa inclusão, o professor além de inovar o processo de ensino aprendizagem, leva para sala de aula um leque de informações para auxiliá-lo no seu trabalho.

As Tecnologias de Informação e Comunicação (TIC) oferecem recursos para favorecer e enriquecer as aplicações e os processos, principalmente na área de educação. A adoção dos recursos das TIC para a aprendizagem abre novas possibilidades para complementar a educação formal. (CARITÁ, PANDOVAN, SANCHES, 2011, p.2).

A educação acompanha de certa forma, o progresso científico e tecnológico da sociedade, mesmo que, 
ainda, de maneira não satisfatória. Nesse sentido, a Informática Educativa representa um meio de estimular e desenvolver as funções perceptivas, cognitivas e sociais dos alunos (OLIVEIRA, 2003).

As tecnologias nas escolas aliada a uma boa proposta pedagógica, facilita ao aluno construir seu próprio conhecimento, e o aluno passa a ter papel ativo na aprendizagem, buscando resolver suas necessidades, resolver situações problemas, realizar pesquisas, etc. (MORAN, 2000, p. 45). É um momento que precisa ser analisado pela comunidade escolar, afim de que se possam buscar metodologias novas que contemplem essa realidade.

Para Levy (2000) o mundo virtual pode simular fielmente o mundo real, mas de acordo com escalas imensas ou minúsculas. Pode permitir ao explorador que construa uma imagem virtual muito diferente de sua aparência física cotidiana... O explorador do mundo virtual deve poder controlar seu acesso a um imenso banco de dados de acordo com princípios e reflexos mentais análogos aos que o fazem controlar o acesso a seu ambiente físico imediato.

As Novas Tecnologias da inteligência individual e coletiva mudam profundamente os dados da inteligência individual e coletiva mudam profundamente os dados dos problemas da educação e da formação. O que é preciso aprender não pode mais der planejado nem precisamente definido com antecedência. Os percursos e perfis de competências são todos singulares e podem cada vez menos ser canalizados em programas ou cursos válidos para todos. E que devemos construir novos modelos do espaço do conhecimento.

Segundo Levy (2000) as reflexões e as práticas sobre a incidência das novas tecnologias na educação desenvolveram-se em vários eixos. Há, por exemplo, numerosos trabalhos versando sobre a multimídia como suporte de ensino ou sobre os computadores como substitutos incansáveis dos professores (ensino assistido por computador). Nessa visão, segundo ele é a mais clássica possível -, a informática oferece máquinas de ensinar. De acordo com outra abordagem, os computadores são considerados como instrumentos de comunicação, de pesquisa de informações, de cálculo, de produção de mensagens (textos, imagens, som) a serem colocados nas mãos dos estudantes.

Diante dessa realidade, delineiam os desafios da escola sobre esse tema na tentativa de responder como ela poderá contribuir para que as crianças e jovens se tornem usuários criativos e críticos dessas ferramentas, evitando que se tornem meros consumidores compulsivos de representações novas de velhos clichês (BELLONI, 2001, p.8).

O que marcará a modernidade educativa será a didática do aprender a aprender, ou do saber pensar, englobando, num só toda a necessidade de apropriação do conhecimento disponível, e seu manejo criativo e crítico... A competência que a escola deve consolidar e sempre renovar é aquela fundada na propriedade do conhecimento como instrumento mais eficaz da emancipação das pessoas e da sociedade. (DEMO, 1995, p.45).

\subsection{Educação na sociedade da informação}

No mundo globalizado, com constantes transformações, é fundamental estarmos preparados para o novo contexto da Era Digital. O mundo, o conhecimento, a sociedade estão em constante modificação e o professor tem de estar preparado para todas essas mudanças. E com a introdução da tecnologia na 
educação o professor tem que conhecer as ferramentas que estão sendo usadas na escola, como a utilização do computador dentro da sala de aula (MORAN, 2006).

A visão do professor como o dono do saber e o aluno um mero receptor de informações está obsoleto. O papel do professor hoje é de dar instruções para que o aluno construa seu próprio conhecimento. $\mathrm{O}$ aluno deixou de ser uma pessoa passiva que apenas recebia informações do professor e passa a ter um papel ativo no processo de ensino aprendizagem, onde também contribui no processo da construção do conhecimento participando de todos os de assuntos abordados.

A educação é entendida como mediação no seio da prática social global. A prática social se põe, portanto como ponto de partida e o ponto de chegada da prática educativa. Daí decorre um método pedagógico que parte da prática social em que professor e aluno se encontram igualmente inseridos ocupando, porém posições distintas, condição para que travem uma relação fecunda na compreensão e encaminhamento da solução dos problemas postos pela prática social (problematização), dispor os instrumentos teóricos e práticos para sua compreensão e solução (instrumentação) e viabilizar sua incorporação como elementos integrantes da própria vida dos alunos (SAVIANI, 2005, p. 263).

O papel de dono do saber não cabe mais ao professor, pois ele não é o detentor absoluto da verdade. Ele tem o papel de transformar a sala de aula num ambiente desafiador e fazer com que o aluno busque a verdadeira essência do conhecimento, além de aumentar sua criticidade do mundo e sua autoestima. Pois não somente o aluno, como também o professor vive num constante processo de formação e transformação.

Mediar significa estar no meio, estar entre, o que poderia ser entendido como barreira, afastando extremidades. Mas o significado de mediação para a educação é oposto. Mediar é estar no meio, para que se possa mais facilmente perceber as necessidades de ambos os lados e interceder buscando um maior equilíbrio. Logo, estar "entre" não é permanecer inerte, sendo apenas uma ponte que interliga extremos. É interagir, construindo um todo significado. (SPONHOLZ, 2003, p. 206).

Quase todas as escolas têm seu laboratório de informática e cabe ao professor, fazer uma mediação entre os alunos e o computador, tira dúvidas e apresenta propostas de trabalho aos mesmos, para que ocorra a construção do conhecimento (MOTTA, 1997).

O professor nunca deixa de ser um aprendiz, deverá sempre buscar novos métodos de ensino, no que implica a utilização de novas ferramentas para auxiliá-lo. Esse preparo de professores para a inclusão das tecnologias em sala de aula, a vontade de aprender e mudar deverá partir do próprio professor, para que depois ele possa buscar uma formação nesse sentido de introdução à tecnologia, para que ele possa aprender e mudar seu método de ensino (TARDIFF, 2002).

A formação de professores para essa nova realidade tem sido crítica e não tem sido privilegiada de maneira efetiva pelas políticas em educação nem pelas Universidades. As soluções propostas inserem-se, principalmente, em programas de qualificação de recursos humanos. O perfil do profissional de ensino é orientado para uma determinada "especialização", mesmo por que, o tempo necessário para essa apropriação não o permite. Como resultado, evidencia-se a fragilidade das ações e da formação, refletidas também através dos interesses econômicos e políticos. (COSTA E XEXÉO, 1997). 
A escola é uma instituição social que se caracteriza como um local de trabalho coletivo voltado para a formação das novas gerações, diferente de outras tantas instituições sociais. Segundo Valente (1999, p. 3), a tecnologia como ferramenta educacional representa um poderoso recurso a ser utilizado pelo aluno em seu processo de aprendizagem, pois permite ao mesmo criar, comunicar-se e resolver problemas.

Nos estudos de Moran (2000), essa escola deve ser uma escola redimensionada para ajudar na construção de cidadãos reais, capazes não só de explicar o mundo, como transformá-lo, em benefício da humanização de todos.

Sabe-se que a melhoria da qualidade do ensino e aprendizagem mediante as implicações que o novo contexto impõe a escola depende, dentre outras condições, do profissional da educação na produção do conhecimento.

“O profissional do ensino é alguém que deve habitar e construir seu próprio espaço pedagógico de trabalho de acordo com limitações complexas que só ele pode assumir e resolver de maneira cotidiana, apoiando necessariamente em visão de mundo, de homem e de sociedade. (Tardiff, 2002, p.149)

No trabalho pedagógico desenvolvido com o uso da tecnologia, o professor é o profissional que vai ajudar na compreensão, utilização, aplicação e avaliação critica das inovações, em um sentido amplo. Assim, o professor em relação as novas tecnologias, tem o papel de utiliza-las de maneira criativa, através de atividades que podem colaborar para tornar suas aulas dinâmica e atrativa. Assim, o aluno terá condições de entrar em contato com material diversificado e construir novos conceitos (MOREIRA, MASINI, 2006, p. 33).

Valente (2005), adverte que o professor ao trabalhar com as novas tecnologias deve estar atento ao processo ensino aprendizagem, uma vez que são inúmeras oportunidades que essas oferecem. A escola tem como função possibilitar aos que nela estão inseridos o seu crescimento intelectual, além de constituirse como um espaço de inclusão sociocultural (GOMES, 2002, p. 88).

As novas tecnologias contribuem para o professor desenvolver ações metodológicas que promovam o desenvolvimento de práticas pedagógicas significativas priorizando o aperfeiçoamento da aquisição do conhecimento.

Assim sendo, o educador precisa estar ciente que as novas tecnologias no espaço escolar é uma contribuição para facilitar a aprendizagem, para tanto todas as atitudes e ações concernentes ao processo devem ser revistas cotidianamente, a fim de se construir um espaço de criação, onde os educandos se sintam livres para agir, tornando-se agente de seu desenvolvimento, sem receber ensinamentos prontos (PERRENOUD, 2000, p. 55).

A prática pedagógica do professor ao utilizar as novas tecnologias no meio educacional, precisa considerar o interesse do aluno, bem como a liberdade para que ele possa criar, escolher e fazer suas próprias produções. Cabe ao professor desenvolver sua prática pedagógica visando estimular seu aluno a querer aprender, a conhecer, enfim a buscar (FREIRE, 2002, p. 109).

Para isso, é fundamental que o professor esteja consciente de que: 
(...) ensinar já não significa transferir pacotes sucateados, nem mesmo significa meramente repassar o saber. Seu conteúdo correto é motivar o processo emancipatório com base em saber crítico, criativo, atualizado, competente. Trata-se, não de cercear, temer, controlar a competência de quem aprende, mas de abrir a chance na dimensão maior possível. Não interessa o discípulo, mas o novo mestre (Demo, 1995, p. 153).

O professor não pode ser repassador de conhecimento, deve ser criador de ambientes de aprendizagem e facilitador do processo de desenvolvimento intelectual do aluno, proporcionando a este o despertar da curiosidade, da dúvida, da pergunta, da investigação e da sua própria criação, desafiando-o a sentir o prazer de aprender (VALENTE, 2005, p. 98).

Segundo Moran (2000, p. 34) adequar a prática pedagógica do professor frente às novas exigências que a sociedade impõe não significa não abandonar os antigos métodos de ensinar, mas utilizá-los dentro de uma visão pedagógica nova e criativa para mediar à aprendizagem e a descoberta, contribuindo para melhoria da qualidade de ensino.

Nesse sentido, a prática pedagógica do professor deve estar voltada entre o real e o virtual, sendo desenvolvida a potencialidade do aluno que está em processo construtivista, e, através da tecnologia, alunos e professores aprendem juntos, conforme é mostrada a proposta de Freire "saber ensinar não é transferir conhecimento, mas criar as possibilidades para sua própria produção ou sua construção". (FREIRE, 2002, p.52).

Moran (2000) contribui com seus estudos, mostrando que as novas tecnologias desempenham diferentes papéis no âmbito educacional. No entanto, algumas vezes estas não são utilizadas de forma que venha contribuir para a melhoria do ensino, diante disso, é papel do professor, ser mediador e facilitador do processo ensino - aprendizagem de seus alunos e proporcionar um ambiente capaz de estabelecer conexões individuais e coletivas.

O professor deve utilizar metodologias que melhor relacione o ensino com as novas tecnologias, uma vez que não basta ao professor possuir apenas conhecimentos técnocientíficos para transmitir aos alunos, é preciso uma série de outras competências relacionadas à didática do saber ensinar, uma vez que "o saber transmitido não possui, em si mesmo nenhum valor formador: somente a atividade de transmissão lhe confere esse valor". (Tardif, 2002, p. 44).

Nesse sentido, cabe ao professor planejar suas aulas e construir uma prática educativa que seja desenvolvida dentro de uma coerência ética, educativa, pedagógica e criativa de conteúdos. Moran (2000, p. 65) entende que a prática pedagógica do professor com as novas tecnologias implica a releitura da função do professor como profissional reflexivo e da escola como organização promotora do desenvolvimento do processo educativo.

Assim sendo, as estratégias pedagógicas do professor devem ser adequadas, capazes de solucionarem as possíveis dificuldades que vão surgindo com as inúmeras oportunidades que o mundo tecnológico oferece (Moran, 2000, p. 65)

Portanto, no desenvolvimento do ensino aprendizagem o professor deve proporcionar uma aprendizagem significativa para seus alunos e ensinar a utilizar a tecnologia de forma significativa, educando 
democraticamente, visando alcançar a todos, para que possam participar discutir e refletir as novas descobertas (BARRETO, 2000).

A informática na escola vem contribuir com uma educação transformadora, com o olhar voltado para o aluno, contribuindo com a formação de cidadãos capazes de observar, opinar, decidir e transformar o meio em que vivem. Para Belloni (2001, p. 55), a informática deve habilitar e dar oportunidade ao aluno para aquisição de novos conhecimentos servindo de complemento aos conteúdos escolares, visando o desenvolvimento integral dos indivíduos.

Motta (1997) afirma que enquanto não forem criadas possibilidades através de substancial mudança na estrutura do ensino continuaremos na situação de dependência e servidão. No entanto, o computador e sua capacidade técnica podem sob forma contraditória, ser usado no sentido da democratização, humanização, transformando as desigualdades existentes na sociedade.

Gomes (2002, p.123) assegura que a tecnologia contribuiu em levar as pessoas a acreditarem que inovação tecnológica é sinônimo de progresso humano; que é circundado por fatores afetivos, cognitivos, sociais e econômicos, sendo que numa economia globalizada isto significa muito mais que uma simples ascensão.

Partindo do princípio que toda pessoa é capaz de aprender, e estas só aprendem a partir da sua ação e interação com o mundo a sua volta, a tecnologia torna-se um importante meio facilitador do processo de aprendizagem desde a primeira etapa da educação, desde a educação infantil ao Ensino Superior (BRANDÃO, 1995).

A mídia-educação se ocupa de muitas questões que constituem seu objeto: a comunicação e a formação; os pontos de vistas instrumentais e temáticos que caracterizam as mídias para formação e a formação para as mídias; a atenção às dimensões expressivas e críticas para escrever/ler com e sobre as mídias; os níveis operativos práticos e teóricos para ensinar as mídias e refletir sobre elas em termos de contextualização, de metarreflexão e de capacitação; os âmbitos da intervenção escolar para a educação formal, informal, extraescolar, tais como animação sociocultural, terceiro setor, empresas sem fins lucrativos e/ou instituições assistenciais, empresas comerciais e formação profissional para atuar nas indústrias da comunicação. (RIVOLTELLA, 2002, p. 99- 107).

\section{O PERCURSO DA PESQUISA}

Este capítulo apresenta a metodologia utilizada para o desenvolvimento da pesquisa, a abordagem teórica, em que se demonstra a descrição dos sujeitos da investigação e as estratégias de recolhimento de dados, bem como o modo como foram tratados. Segundo Gil (2002), pode-se definir pesquisa como o procedimento racional e sistemático, que tem o objetivo de responder aos problemas propostos. Ela é requerida quando não se tem respostas suficientes ao problema ou quando as respostas se encontram em estado de desordem onde não possam ser relacionadas adequadamente ao problema.

Trata-se de uma pesquisa básica bibliográfica, elaborada a partir de material já publicado, constituído principalmente de livros, artigos de periódicos e materiais disponibilizados na internet, que defendem a importância da informática como uma ferramenta a mais que a escola dispõe para favorecer o prazer do aluno em construir seu próprio conhecimento. Para Gil (2002), a pesquisa bibliográfica é desenvolvida 
com base em material já elaborado como livros e artigos científicos, a principal vantagem dessa pesquisa é o fato de permitir ao investigador a cobertura de uma gama de fenômenos muito mais ampla do que aquela que poderia pesquisar diretamente.

Em relação à sua natureza, foi desenvolvida uma pesquisa qualitativa, sendo que esse tipo de abordagem é inerente ao pesquisador, pois permite trabalhar com os sentimentos e falas dos envolvidos no estudo, Gil (2002, p.21 e 22), esclarece que o método qualitativo caracteriza-se pela "construção do conhecimento a partir de hipóteses e interpretações que o pesquisador constrói”.

A pesquisa se pautou em um trabalho de campo, que segundo Marconi e Lakatos (2004, p. 125), "baseiase na observação dos fatos tal como ocorrem na realidade", com a aplicação de questionários (ANEXOS $\mathrm{D}$ e E).

\subsection{Caracterização da pesquisa}

Como instrumentos fundamentais de coleta de dados utilizou-se um questionário respondido pelos participantes.

Após a aplicação do questionário, as respostas obtidas foram analisadas, a partir de categorias de análise que emergiram do arcabouço teórico, ou seja, cada resposta foi interpretada e comentada logo em seguida, com base na teoria antes exposta. Trata-se ainda de pesquisa caracterizada pela ação participativa.

Após a coleta de dados foi feita de forma a permitir respostas aos questionamentos da pesquisa, sendo realizada a etapa de apresentação e análise qualitativa dos resultados obtidos culminando com a organização dos dados para a produção das considerações finais. Segundo Gil (2002), a análise dos dados pode ser definida como uma sequência de atividades, que envolve a redução dos dados, a categorização desses dados, sua interpretação e a redação de relatório. A interpretação foi feita através do processo de analogia com os estudos assemelhados, de forma que os resultados obtidos foram comparados com resultados similares para destacar pontos em comum e pontos de discordância.

\subsection{O curso de Ciências Contábeis na Faculdade de Iporá- FAI}

\subsubsection{Concepção do curso}

Objetivos do curso

\subsubsection{Objetivos gerais}

Esta vocação regionalista, assumida no inicio do curso, posteriormente assimila novos objetivos, mediante transformações sociais, colocada pela organização.

O curso de graduação em Ciências Contábeis vai ensejar condições para que o futuro contabilista seja capacitado a:

- Compreender questões científicas, técnicas e sociais, econômicas e financeiras, em âmbito nacional e internacional e nos diferentes modelos de organização; 
- Apresentar pleno domínio das responsabilidades funcionais envolvendo apurações, auditorias, perícias, arbitragens, noções de atividades atuariais e quantificações de informações financeiras, patrimoniais e governamentais, com a plena utilização de inovações tecnológicas;

\subsubsection{Específico}

- Formar profissionais preparados para lidar com os dados empresariais e contábeis; utilizando adequadamente a terminologia e a linguagem da Ciências Contábeis e Atuariais; demonstrando visão sistêmica e interdisciplinar da atividade contábil na elaboração de relatórios que contribuam para desempenho eficiente e eficaz de seus usuários, quaisquer que sejam os modelos organizacionais;

- Aplicar adequadamente a legislação inerente às funções contábeis;

- Desenvolver, com motivação e através de permanente articulação, a liderança entre equipes multidisciplinares para a captação de insumos necessários aos controles técnicos, à geração e disseminação de informações contábeis, com reconhecido nível de precisão.

\subsubsection{Perfil do egresso}

O curso de Ciências Contábeis da FAI pretende formar profissionais que aliem a compreensão dos fundamentos da ciência Contábil a uma visão global atualizada da sociedade moderna, com competências e habilidades generalistas para participar, interferir e propor alternativas para o desenvolvimento e melhoria da qualidade de vida da sociedade, fundamentada nas Ciências Contábeis, na instrumentalização técnica e na iniciativa, com postura ética e consciência de sua responsabilidade social e valores, qualificando-os para ter ações específicas à habilitação em Ciências Contábeis, tais como:

- Compreender as questões cientifica, técnicas e sociais, econômicas e financeiras em âmbito nacional e internacional e nos diferentes modelos de organização;

- Apresentar pleno domínio das responsabilidades funcionais envolvendo apurações, auditorias, perícias, arbitragens, noções de atividades atuariais e quantificações de informações financeiras, patrimoniais e governamentais, com a plena utilização de inovações tecnológicas;

- Revelar capacidade clinico-analítica de avaliação, quanto às implicações organizacionais com a o advento da tecnologia da informação.

- Usar e adequar a terminologia e a linguagem da Ciência Contábeis, demonstrando visão sistêmica e interdisciplinar da atividade contábil;

- Elaborar relatórios que contribuam para desempenho eficiente e eficaz de seus usuários, quaisquer que sejam os modelos organizacionais;

- Aplicar adequadamente a legislação inerente às funções contábeis;

- Desenvolver, com motivação mediante permanente articulação, a liderança entre equipes multidisciplinares para a captação de insumos necessários aos controles técnicos, à geração e disseminação de informações contábeis, com reconhecido nível de precisão.

\subsubsection{Perfil do profissional a ser formado}

O processo pedagógico deve garantir que o graduando demonstre ao final do curso um perfil que envolva: internalização de valores de responsabilidade social, justiça e ética profissional; formação humanística e 
visão global que o habilite a compreender o meio social, político, econômico e cultural onde está inserido e a tomar decisões em um mundo diversificado e interdependente;

O profissional com formação técnica e científica para atuar na contábil das organizações, além de desenvolver atividades específicas da prática profissional em consonância com as demandas mundiais, nacionais e regionais; competência para empreender, analisando criticamente as organizações, antecipando e promovendo suas transformações; capacidade de atuar em equipes multidisciplinares; capacidade de compreensão da necessidade do contínuo aperfeiçoamento profissional e do desenvolvimento da autoconfiança.

\subsubsection{Atribuições no Mercado de Trabalho}

Em sua formação, o Contador assimila conhecimentos das mais diversas áreas, a Faculdade de Iporá desenvolve um projeto político pedagógico voltado para formação de profissionais com valores humanistas éticos.

O Contador graduado por essa instituição exercerá suas responsabilidades com expressivo domínio das funções contábeis, incluído noções de atividades atuariais e de quantificações de informações financeiras, patrimoniais e governamentais, que viabilizem aos agentes econômicos e aos administradores de qualquer segmento produtivo ou institucional o pleno cumprimento de seus encargos quanto gerenciamento, aos controles e à prestação de contas de sua gestão perante a sociedade.

Deverá, ainda, gerar informações para tomada de decisão, organização de atitudes e construção de valores orientados para a cidadania. Desenvolver, analisar e implantar sistemas de informação contábil e de controle gerencial, revelando capacidade critica e analítica para avaliar as implicações organizacionais com tecnologia da informação, exercer com ética e proficiência as atribuições prerrogativas que lhe são prescritas através da legislação especifica, revelando domínios adequados aos diferentes modelos organizacionais.

O elemento nobre do projeto pedagógico é a organização curricular, pois é ela que garante a formação e assegura a relevância, o significado e o caráter científico de uma área de conhecimento. Certifica ainda a formação profissional competente e politicamente comprometida com a criação de uma sociedade justa e humana. Esta estrutura curricular possibilita o mínimo de conteúdo disciplinar indispensável à apropriação do conhecimento relevante em termos dos conteúdos das ciências contábeis, permitindo a síntese necessária do teórico e do prático (ALMEIDA, 2003).

Neste sentido, o currículo do curso foi concebido como um instrumento que oferece ao educando a oportunidade de construir a sua própria formação ética, intelectual e profissional. $\mathrm{O}$ currículo pleno do curso, operacionalizado pelos planos de ensino de cada disciplina ou atividade, caracteriza-se, portanto, por uma orientação de permanente estímulo à imaginação e à criatividade e inovação, procurando exercitar o raciocínio analítico, inspirar a capacidade de realização e desenvolver as habilidades de comunicação e expressão.

O currículo pleno atende às necessidades do meio social, sendo organicamente articulado, permeável às demandas de entradas e reentradas, tanto de clientela como de conteúdos, em busca de modelos institucionais que estejam mais próximos dos fatos, mais aptos a fomentar lhes a força criadora. Incorpora 
algumas características indispensáveis à formação do cidadão e do profissional de nosso tempo: comunicação interpessoal, ética profissional, recursos computacionais e uso intenso da informática e outros recursos da moderna tecnologia educacional (ALMEIDA, 2001).

A perspectiva institucional encaminha-se para a formação dos profissionais contábeis com competência para dar respostas simultaneamente aos imperativos da integração mundial e nacional e às necessidades específicas da comunidade Iporaense.

O currículo do curso é composto por conteúdos de formação básica e profissional que representam a contribuição das diversas ciências para a formação do perfil profissional do contador. Ao se fazerem presentes na estrutura curricular, as diferentes ciências são apresentadas de forma articulada, definindo a necessidade dos professores das várias áreas terem clareza sobre quais conhecimentos são fundamentais para o curso, sobre que perspectivas devem ser trabalhadas para o desenvolvimento de uma efetiva interdisciplinaridade (ALMEIDA, 2000).

Para garantir a prática interdisciplinar no contexto pedagógico do curso de Ciências Contábeis, o currículo se organiza observando a verticalização do conhecimento, na medida em que evolui nas suas especificidades, no sentido crescente de complexidade e especialização. Por outro lado, garante-se também a sua organização horizontal, nucleando as diversas áreas do conhecimento em conjuntos que formam as séries do curso, sob a forma de disciplinas e/ou atividades, no sentido de permitir o desenvolvimento das diferentes habilidades definidas para o curso.

Assim, o currículo procura privilegiar, nas séries iniciais, preferencialmente, as disciplinas básicas e de fundamentos que procuram garantir as habilidades de expressão oral e escrita, raciocínio lógico, crítico e analítico, postura investigativa frente ao conhecimento e desenvolvimento de valores éticos, entre outros. O trabalho com essas habilidades não se esgota, contudo, neste momento, ao longo do curso, outras disciplinas delas se ocuparão. Nestas séries busca-se ainda possibilitar a compreensão do contexto socioeconômico e político em constante transformação, no qual as políticas e os agentes econômicos estão inseridos, bem como a dinâmica própria dessas relações.

Nas séries finais, o currículo estabelece diretivas gerais sobre a evolução provável do campo de atuação do contador nos próximos anos, mais especificamente, nas áreas de auditoria, perícia contábil, no campo gerencial, no mercado de fusões, planejamento, tributação e atuação no cenário internacional.

O currículo proposto, contudo, não é uma obra acabada e intocável. É um instrumento dinâmico, vivo, acompanhando e, até mesmo, antecipando-se às mudanças, aos avanços tecnológicos, às mutações dos perfis de mercado e do profissional, atento aos movimentos sociais e econômicos, regionais, nacionais e internacionais. Esta flexibilidade permitirá aos estudantes desenvolver vocações, interesses e potenciais específicos individuais, sem perda, entretanto, do foco principal do curso.

Para atender a essa flexibilidade, além da possibilidade das alterações periódicas nos planos de ensino de cada disciplina, optou-se por reservar, na grade curricular, espaço para disciplinas optativas cujo conteúdo temático será flexível, adaptado aos temas da atualidade, contemporâneos à sua ministração. Servirá para a discussão e experimentação de novas técnicas e métodos na área contábil, e para a introdução de novos conteúdos. 
É importante ressaltar que os programas das disciplinas estarão em permanente atualização e antes do início de cada período letivo, passarão por uma completa revisão, para melhor se adaptar às necessidades atuais e às exigências do mercado. Para cada período, o programa de disciplina será atualizado suas ementas, objetivos, conteúdo programático e bibliografia.

A relação teoria/prática se materializa na Elaboração do Trabalho de Curso que pretende ser sempre a "expressão do conhecimento" adquirido ao longo do Curso, e construído progressivamente pelo concurso de atividades realizadas em todas as disciplinas.

Entre as atividades extracurriculares que os alunos praticarão estão às excursões e os trabalhos de campo, as palestras com profissionais reconhecidos no mercado e com pesquisadores eminentes da contabilidade no Brasil.

\subsubsection{Estrutura curricular}

\section{Dimensionamento da carga horária das unidades de estudo}

O curso de Graduação em Ciências Contábeis da Faculdade de Iporá está estruturado de acordo com a Resolução n. ${ }^{\circ}$ 10/2004, que estabelece as Diretrizes Curriculares Nacionais, que fixa o conteúdo para o referido curso.

O Currículo do Curso abrange uma sequência de disciplinas e atividades ordenadas por matrículas semestrais por disciplina em uma seriação considerada adequada para o encadeamento lógico de conteúdos e atividades.

As disciplinas propostas para o referido curso e a carga horária das mesmas são apresentadas no quadro “organização curricular" a seguir:

\section{MATRIZ CURRICULAR DE CIÊNCIAS CONTÁBEIS 2016/1}

$1^{\circ}$ Período

1. Contabi

lidade

Geral I

2. Funda

60

mentos da

Administr

ação

3. Matem ática

4. Comuni
Prática

60

-
Total

60

cação e
60

60

$-$

-
60

03

03 
Expressão

5.

60

60

03

Introduçã

o ao

Direito

6. Funda

80

80

04

mentos

das

Ciências

Sociais e

do Compo

rtamento

\section{Total}

$2^{\circ}$

Período

1. Contabi

60

60

03

lidade

Geral II

2. Matem

60

60

03

ática

Financeira

3. Gestão

60

60

03

Organizac

ional

4.

40

40

02

Legislaçã

o Empresa

rial

5. Gestão

40

40

02 de

Recursos

Materiais

e Patrimo

niais 
6.

60

40

40

80

04

olvimento

do Conhe

cimento

Científico

\section{Total}

360

40

400

20

$3^{\circ}$ Período

1. Contabi

Teórica

60

Prática

Total

60

03

lidade Inte

rmediária

2. Contabi

60

60

03

lidade e

Custos

3.

Raciocíni

o Lógico

4. Ética Pr

ofissional

5. Gestão

60

60

03

de

Sistemas

de Inform

ações

6.

60

60

03

Processo

Contábil e

Tributário

7. Funda 80

03

4

03

\author{
Aulas
}


Legais.

\section{Total}

$4^{\circ}$

\section{Período}

1. Contabi

lidade do

Terceiro

\section{Setor}

2. Contabi

60

lidade

Comercial

3.

60
400

Prática

Total
60

03
60

03

60

03

Economia

Empresari

al

4. Gestão

60

60

03

Financeira

e Orçame

ntária I

5. Direito

40

40

02

Comercial

6. Funda

80

80

04 osóficos, Éticos e R esponsabil idade Soci oambienta

1.

\section{Total}

$5^{\circ}$

360

Teórica

\section{Período}

1.

18

Prática

Total

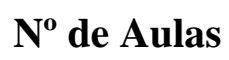

Atividade 
Integrador

a I

2. Análise

60

60

03

de

Balanço

3. Contabi

60

60

03

lidade

Avançada

4. Gestão

60

60

03

Financeira

e Orçame

ntária II

5. Contabi

60

60

03

lidade

Tributária

6. Eletiva

60

60

03

do Grupo

A/B ou C

Total

$6^{\circ}$

\section{Período}

1.

60

360

18

Prática

Total

$\mathrm{N}^{\circ}$ de Aulas

60

03

Atividade

Integrador

a II

2. Contabi

60

60

03

lidade

Gerencial

3. Contabi

60

60

03

lidade no

Planejame

nto e

Controle

Empresari 
al

4. Sistema

60

60

03

Financeir

o e

Mercado

de

Capitais

5.

60

60

03

Legislaçã

o Trabalhi

sta e Previ

denciária

6.

40

40

80

04

Liderança,

Criativida

de e Empr

eendedori

smo.

7. Práticas

60

60

03

Contábeis

I

8. Eletiva

60

60

03

do Grupo

A/B ou C

\section{Total}

460

40

500

25

$7^{0}$

Teórica

Prática

Total

$\mathbf{N}^{0}$ de Aulas

Período

1.

60

60

03

Atividade

Integrador

a III

2. Teoria

60

60

03

da Contab

ilidade 
lidade do

Agronegó

cio

4. Contabi

lidade

Pública

5. Contabi

lidade

Atuarial

6.

60

60

Auditoria

Contábil I

7. Práticas

Contábeis

II

8. Eletiva

do Grupo

A/B ou C

Total

$8^{\circ}$

\section{Período}

1.

Atividade

Integrador

a IV

2. Arbitra

60

60

03

gem e

\section{Perícias}

3.

60

60

03

Auditoria

Contábil

II

4. Tópicos 
Contempo

râneos em

Negócios

5. Consult

60

60

03

oria e Con

troladoria

Contábil

6. Libras

60

60

03

(Optativa)

7. Eletiva

60

60

03

do Grupo

A/B ou C

8. Práticas

180

180

Contábeis

III

\section{Total}

420

180

600

21

DISCRI

Teórica

Prática

Total

N. Aulas

MINAÇÃ

O

Carga

2040

2040

102

Horária

das Disci

plinas Es

pecíficas

Carga

480

80

560

28

Horária

das Disci

plinas de

Núcleo

Comum

Disciplin

as

\section{Eletivas}

Libras

60

60 
(Optativa)

Estágio S

upervisio

nado -

Práticas

Contábei

s I, II e

III.

Atividade

s Integra

doras

Atividade

s Comple

mentares

Total do

3060

380

3760

163

Curso 